\title{
New Gaussian Plume Equation for the Impacts of Dust Storms on Radionuclide Transport
}

\author{
Bashar M. Al-Zghoul", Wa'il Y. Abu-El-Sha'r \\ Civil Engineering Department, Jordan University of Science and Technology, 22110 Irbid, Jordan
}

\begin{abstract}
Potential impacts of dust storms on radionuclide atmospheric dispersion have been the focus of great attention lately by countries that opted to build nuclear power plants in arid regions. The Gaussian point source dispersion equations have been modified to incorporate the rate of scavenging of gaseous radioactive plumes emitted from nuclear power plants due to adsorption by nanoaerosols that come from dust storms. The radionuclide-nanoaerosol interaction has been built based on the flux-matching theory assumptions: the size of a particle has the same order of magnitude of the mean free path of the molecules of air, and the adsorption coefficient is time-dependent. A correction factor $\left(\lambda_{r}\right)$ has been introduced to the Gaussian plume equation to represent the fraction of the remaining radionuclides in the atmosphere at any distance downwind. A case study involving iodine-131 was used to apply the modified equations and to estimate the correction factor for different dust storms. The fraction of the adsorbed radionuclides on the atmospheric nanoaerosols $\left(1-\lambda_{r}\right)$ varies from less than 0.1 during a dust storm that has a density of $10 \mu \mathrm{g} \mathrm{m}^{-3}$ to more than 0.9 during a heavy dust storm of $1000 \mu \mathrm{g} \mathrm{m} \mathrm{m}^{-3}$ of density. Therefore, 90 percent of the transported radionuclide plume can be adsorbed by the atmospheric nanoparticles during the heavy dust events, while less than 10 percent can be adsorbed on the atmospheric nanoaerosols in normal days. These findings pose new challenges since radionuclides can be carried by nanoaerosols to farther distances than what is normally expected.
\end{abstract}

Keywords: Nanoaerosols; Dust storms; Radionuclides; Gaussian dispersion.

\section{INTRODUCTION}

Atmospheric nuclear emissions (radionuclides) from nuclear power plants are one of the most dangerous emissions to the environment (EPA, 2000). They can harm humans, animals, plants and all environmental components within several kilometers from their source. These emissions along with those from other power plants or industrial activities disperse in plumes into the atmosphere and have been commonly modelled by the atmospheric diffusion-dispersion equation that is represented by the Gaussian plume equation (GPE) (Masters and Ela, 2007). Radionuclide transport in the atmosphere depends mainly on several parameters and conditions, most of which greatly depend on the climate of the region of interest, such as atmospheric stability and wind speed. However, many other conditions can affect radionuclide plume transport, such as the amount of effluent released into the atmosphere, the removal mechanisms of the released effluent, the height of the release, the momentum and buoyancy of the emitted plume, the geographic features and some other

\footnotetext{
${ }^{*}$ Corresponding author.

Tel.: + 962776992163

E-mail address: bmalzghoul16@eng.just.edu.jo
}

conditions (NRC, 1977).

Areas that are affected by unusual weather conditions such as sand and/or dust storms cover the region of interest with huge amounts of dust for a long period of time. Under such conditions, the behavior of the emitted radionuclides and the potential effects on the emission plumes have not been studied as revealed by a literature review on the subject (Engelstaedter et al., 2006; Abed et al., 2009; Athanasopoulou et al., 2016), meaning that there is a real need to understand and model such impacts. Countries (including Egypt, United Arab Emirates and Jordan) that are affected by Khamaseen storms and opted to build nuclear power plants (Ganor et al., 1981; Alpert and Ganor, 2001; Shahsavani et al., 2012; Krasnov et al., 2013; Alghamdi et al., 2015; Saraga et al., 2017; Jaafari et al., 2017) have a greater need and concern.

The existence of the dust in the atmosphere is different from one region to another and depends on several conditions such as location, rate of precipitation, and the general meteorology of the region during the year. Jordan, like most of the countries in the Middle East, is exposed annually to several dust storms that come from the Sahara of North Africa (Abed et al., 2009). These dust storms (locally known as Khamaseen cyclones) reform frequently in a limited period of spring each year and can travel thousands of kilometers from the North African Sahara to reach the Eastern Mediterranean region carrying a huge amount of 
dust and aerosols that makes a significant change in the environmental stability and changes in the climate of the countries through which they pass.

The Khamaseen cyclones, with their heavy load of nanoaerosols, can make an effect on the transported radionuclide concentration emitted from the nuclear plants due to the potential sorption of these radionuclides onto the large surface area of the nanoaerosols, making them spread in a long distance. However, such effects have not been studied yet simply because the Khamaseen cyclones and these types of extreme events are not widespread around the world, especially the countries that use nuclear power plants. Nevertheless, impacts of dust storms on the building in regions subjected to these storms have been investigated by Doronzo et al. (2014, 2015). In summary, the potential impacts of the dust on the emitted radionuclides and their transportation in the atmosphere are not well understood and need further exploration.

In this study, the commonly used Gaussian point source equations have been modified to incorporate the potential interaction between the emitted radionuclides and the nanoaerosols from dust storms. Results are compared with the available experiment of Noguchi et al. (1990) on adsorption of the gaseous iodine-131 on atmospheric nanoaerosols.

\section{MODEL DEVELOPMENT}

When radionuclides or any other emitted pollutants are applied to the porous medium of the aerosols in the atmosphere, these radionuclides do not act as a conservative tracer, due to the electrical charge difference between the aerosols, which have a negative charge, and the radionuclides, which may make a strong bond on the huge surface area of the aerosols due to the adsorption phenomenon (Tindall, 1999). The general diffusion-dispersion equation with a reaction term represents the rate of scavenging of radionuclides due to adsorption by atmospheric nanoparticles as shown in Eq. (1).

$$
\frac{\partial C}{\partial t}+\bar{u} \frac{\partial C}{\partial t}=K_{x x} \frac{\partial^{2} C}{\partial x^{2}}+K_{y y} \frac{\partial^{2} C}{\partial y^{2}}+K_{z z} \frac{\partial^{2} C}{\partial z^{2}}+R(c, t)
$$

where $C$ is the concentration of diffused molecules (radionuclides), $t$ is the time, $\bar{u}$ is the average wind speed, $K_{x x}, K_{y y}$ and $K_{z z}$ are the diffusivity constants for the diffused molecules in the three dimensions, and the last term represents the reaction term as a function of concentration and time.

In this study, the reaction term was represented by the flux-matching theory approach. This theory was suggested by Fuchs et al. (1964), Loyalka et al. (1983), Lushnikov et al. (2004) and Hales et al. (2002) and developed by Elperin et al. (2017) to estimate the scavenging coefficient (the adsorption coefficient) as a function of time. This coefficient represents the rate of adsorption of gaseous radionuclides (pollutants) emitted from smoke stacks in industrial activities on atmospheric nanoaerosols. The following assumptions are the main assumptions made for determining the adsorption coefficient based on flux-matching theory:
(1) The size of nanoaerosols has the same order of magnitude as the mean free path of air molecules (lies in the transition regime; Knudsen number $K_{n}=1$ ) (Seinfeld and Pandis, 2006). (2) Aerosol particles are uniformly distributed in the plume area. (3) Aerosol particles and trace gas molecules have the same velocity, which is equal to the wind speed. (4) Pollutants are in the gaseous phase. Following a similar approach to that suggested by Elperin et al. (2013) and Elperin et al. (2018), the reaction term of the general diffusiondispersion equation is represented by Eq. (2).

$$
\begin{aligned}
\frac{\partial C_{G}}{\partial t} & =\left(\gamma+\frac{m \varphi_{s} \tau_{D}{ }^{-1} \exp \left(-\frac{1+m \varphi_{s}}{\tau_{D}}\right) t}{1-\frac{1+m \varphi_{s}}{m \varphi_{s}}\left(1-\exp \left(-\frac{1+m \varphi_{s}}{\tau_{D}} t\right)\right)}\right)-C_{G} \\
& =-\lambda(t) c
\end{aligned}
$$

where $c$ is the concentration of gaseous radionuclides $\left(\mathrm{g} \mathrm{m}^{-3}\right)$, $\lambda(t)$ is the scavenging coefficient $\left(\mathrm{s}^{-1}\right), \gamma$ is the radioactive decay constant $\left(\mathrm{s}^{-1}\right), m$ is the adsorption coefficient (given by $m=K^{\prime} S_{s p}$; which is dimensionless and depends on the linear adsorption coefficient of radionuclides on atmospheric nanoaerosols $K^{\prime}(\mathrm{cm})$, and the specific surface area of the aerosols $\left.S_{s p}\left(\mathrm{~m}^{2} \mathrm{~cm}^{-3}\right)\right), \tau_{D}$ is the characteristic time of mass transfer (s) (given by $\tau_{D}=a m / 3 K_{G}$; depends on the radius of the aerosol particle $a(\mathrm{~m})$, the dimensionless adsorption coefficient $m$, and the coefficient of mass transfer $K_{G}\left(\mathrm{~m} \mathrm{~s}^{-1}\right)$ ), and $\varphi_{s}$ represents the volume fraction of the aerosol particles in the atmosphere (given by $\varphi_{s}=n(4 / 3) \pi a^{3}=\rho_{D} / \rho_{s}$ where $n$ is the number concentration of aerosols, $\rho_{D}$ is the mass concentration of aerosols per unit volume of air $\left(\mu \mathrm{g} \mathrm{m}^{-3}\right)$, and $\rho_{s}$ is the density of aerosols $\left.\left(\mu \mathrm{g} \mathrm{m}^{-3}\right)\right)$. Substitution of Eq. (2) in the reaction term of Eq. (1) is shown in Eq. (3).

$$
\frac{\partial C}{\partial t}+\bar{u} \frac{\partial C}{\partial x}=K_{x x} \frac{\partial^{2} C}{\partial x^{2}}+K_{y y} \frac{\partial^{2} C}{\partial y^{2}}+K_{z z} \frac{\partial^{2} C}{\partial z^{2}}-\lambda(t) c
$$

To simplify the term that represents the scavenging coefficient, the following assumptions are applied: $l=$ $m \varphi_{s} / \tau_{D}, b=\left(m \varphi_{s}+1\right) / \tau_{D}, s=m \varphi_{s} /\left(m \varphi_{s}+1\right)$, and $d=1-s$. Substitution of $l, b, s$ and $d$ in Eq. (3) is shown in Eq. (4).

$$
\begin{aligned}
\frac{\partial C}{\partial t}+\bar{u} \frac{\partial C}{\partial x} & =K_{x x} \frac{\partial^{2} C}{\partial x^{2}}+K_{y y} \frac{\partial^{2} C}{\partial y^{2}}+K_{z z} \frac{\partial^{2} C}{\partial z^{2}} \\
& -\left(\gamma+\frac{a}{d e^{b t}+s}\right) c
\end{aligned}
$$

This equation has been solved subject to initial and boundary conditions of $C(x, y, z, 0)=S \delta(x) \delta(y) \delta(z)$ and $C(x, y, z, t)=0$ when $x, y, z \rightarrow \mp \infty$, respectively, where $S$ represents the source strength from instantaneous point source and $\delta(x), \delta(y)$ and $\delta(z)$ the Dirac-delta function in the three dimensions. Applying separation-of-variables technique, the concentration is divided into three components in the $x$, 
$y$ and $z$ directions as shown in Eq. (4). Initial conditions of the three components are $C(x, 0)=S^{1 / 3} \delta(x), C(y, 0)=S^{1 / 3} \delta(y)$, and $C(z, 0)=S^{1 / 3} \delta(z)$.

$C(x, y, z, t)=C_{x}(x, t) C_{y}(y, t) C_{z}(z, t)$

Based on the assumption in Eq. (5), Eq. (4) is reduced to the following:

$$
\begin{aligned}
& \frac{\partial C_{x}}{\partial t}+\bar{u} \frac{\partial C_{x}}{\partial x}=K_{x x} \frac{\partial^{2} C}{\partial x^{2}}-\left(\gamma+\frac{l}{d e^{b t}+s}\right) C \\
& \frac{\partial C_{y}}{\partial t}=K_{y y} \frac{\partial^{2} C_{y}}{\partial y^{2}} \\
& \frac{\partial C_{z}}{\partial t}=K_{z z} \frac{\partial^{2} C_{z}}{\partial z^{2}}
\end{aligned}
$$

Each of Eqs. (6)-(8) can be solved independently by using Fourier transform to form the full solution of the GPE. The reaction term is assumed to be in the $x$ direction only because the plume spread in the $x$ direction is much higher than that in the other directions. To begin the solution of Eq. (6) (in the $x$ direction), Fourier transform is applied on each term of Eq. (6), which gives

$\frac{\partial C}{C(\alpha, t)}=-\left[i \alpha \bar{u}+K_{x x} \alpha^{2}\right]+\left(\gamma+\frac{l}{d e^{b t}+s}\right) \partial t$

Taking the integration of the two sides of Eq. (9) gives

$$
C(\alpha, t)=C_{1}(\alpha, t) \exp \left[-\left(i \alpha \bar{u}+K_{x x} \alpha^{2}+\gamma\right) t\right]\left(\frac{d e^{b t}+s}{e^{b t}}\right)
$$

The integration constant $C_{1}(\alpha, t)$ refers to the initial concentration (at $t=0$ ), which is $C_{1}(\alpha, 0)$, and can be obtained by applying Fourier transform on the initial condition, giving $C(x, 0)=S^{1 / 3} \delta(x)$ and $C_{1}(\alpha, 0)=S^{1 / 3} /(2 \pi)^{1 / 2}$ where $S$ is the source strength from instantaneous point source. Substitution of the constant of the integration in Eq. (10) gives

$C(\alpha, t)=\frac{S^{1 / 3}}{(2 \pi)} \exp \left[-\left(i \alpha \bar{u}+K_{x x} \alpha^{2}+\gamma\right) t\right]\left(\frac{d e^{b t}+s}{e^{b t}}\right)$

By applying the inverse Fourier transform on Eq. (11), $C(x, t)$ becomes as follows:

$$
\begin{aligned}
& C(x, t)= \\
& \frac{1}{(2 \pi)^{1 / 2}} \int_{-\infty}^{\infty} \frac{S^{1 / 3}}{(2 \pi)^{1 / 2}} e\left[-\left(i \alpha \bar{u}+K_{x x} \alpha^{2}+\gamma\right) t\right] e^{i \alpha x}\left(\frac{d e^{b t}+s}{e^{b t}}\right) d \alpha
\end{aligned}
$$

This equation is an integration with respect to the variable $\alpha$. Using completing-the-square technique, it can be simplified to give the following:

$C(x, t)=\frac{S^{1 / 3} e^{-\gamma t}}{2 \pi}\left(\frac{d e^{b t}+s}{e^{b t}}\right) \int_{-\infty}^{\infty} e^{-\left(\alpha\left(K_{x x} t\right)^{1 / 2}-\frac{i(x-\bar{u} t)}{2\left(K_{x x} t\right)^{1 / 2}}\right)^{2}-\frac{(x-\bar{u} t)^{2}}{4 K_{x x} t}} d \alpha$

To solve this equation, it is assumed that $\omega=\alpha\left(K_{x x} t\right)^{1 / 2}-$ $i(x-u \bar{t}) /\left[2\left(K_{x x} t\right)^{1 / 2}\right]$, and thus Eq. (13) gives

$C(x, t)=\frac{S^{1 / 3} e^{-\gamma t}}{2 \pi\left(K_{x x} t\right)^{1 / 2}} e^{-\frac{(x-\bar{u} t)^{2}}{4 K_{x x} t}}\left(\frac{d e^{b t}+s}{e^{b t}}\right) \int_{-\infty}^{\infty} e^{-\omega^{2}} d \omega$

Knowing that $\int_{-\infty}^{\infty} e^{-\omega^{2}} d \omega=\sqrt{\pi}$ and $\left(\frac{d e^{b t}+s}{e^{b t}}\right)=(d+$ $\left.s e^{-b t}\right)$, Eq. (14) gives

$C(x, t)=\frac{S^{1 / 3}}{\sqrt{2 \pi}\left(2 K_{x x} t\right)^{1 / 2}} \exp \left(-\frac{(x-\bar{u} t)^{2}}{4 K_{x x} t}-\gamma t\right)\left(d+s e^{-b t}\right)$

This is the solution of the general diffusion-dispersion equation in the $x$ direction. To complete the solution, Eqs. (7) and (8), have been solved in the same way, resulting in Eqs. (16) and (17).

$$
\begin{aligned}
& C(y, t)=\frac{S^{1 / 3}}{\sqrt{2 \pi}\left(2 K_{y y} t\right)^{1 / 2}} \exp \left(-\frac{y^{2}}{4 K_{y y} t}\right) \\
& C(z, t)=\frac{S^{1 / 3}}{\sqrt{2 \pi}\left(2 K_{z z} t\right)^{1 / 2}} \exp \left(-\frac{z^{2}}{4 K_{z z} t}\right)
\end{aligned}
$$

The terms that include the diffusivity constants can be represented by the standard deviation and variance in the three dimensions (Seinfeld and Pandis, 1998) as $\sigma_{x}^{2}=2 K_{x x} t$, $\sigma_{y}{ }^{2}=2 K_{y y} t$ and $\sigma_{z}{ }^{2}=2 K_{z z} t$. The standard deviation in the three dimensions can be determined using Pasquill-Gifford curves (Pasquill, 1961) or the practical equations of Martin et al. (1976) as functions of both the distance downwind and the atmospheric stability classes of Turner et al. (1970). Consequently, the full solution of the general diffusiondispersion equation based on Eq. (5) is given by Eq. (18).

$$
\begin{aligned}
& C(x, y, z, t) \\
& =\frac{S\left(d e^{-\gamma t}+s e^{-(b+\gamma) t}\right)}{(2 \pi)^{2 / 3} \sigma_{x} \sigma_{y} \sigma_{z}} \exp \left(-\frac{(x-\bar{u} t)^{2}}{2 \sigma_{x}^{2}}-\frac{y^{2}}{2 \sigma_{y}^{2}}-\frac{z^{2}}{2 \sigma_{z}^{2}}\right)
\end{aligned}
$$

This formula represents the concentration of the diffused particles for an instantaneous point source $(S)$ at any point 
downwind. However, the GPEs for a continuous point source (q) have been estimated based on the Lagrangian approach, taking the time integration of the concentration for the instantaneous point source from 0 to $\infty$, as shown in Eq. (19).

$$
\begin{aligned}
& C(x, y, z) \\
& =\lim _{t \rightarrow \infty} C(x, y, z, t) \\
& =\lim _{t \rightarrow \infty} \int_{0}^{t} Q\left(x, y, t \mid 0,0, t^{\prime}\right) Q\left(z, t \mid H, t^{\prime}\right) q\left(d e^{-\gamma t}+s e^{-(b+\gamma) t}\right) d t^{\prime}
\end{aligned}
$$

where $Q\left(x, y, t \mid 0,0, t^{\prime}\right)$ is the transition probability in the $x$ and $y$ directions, and $Q\left(z, t \mid H, t^{\prime}\right)$ is the transition probability in the $z$ direction as a function of the smoke stack height $H$ in case of total reflection of the diffused material on the ground surface (Seinfeld and Pandis, 2006). These two functions are elaborated in Eqs. (20) and (21),

$$
Q\left(x, y, t \mid 0,0, t^{\prime}\right)
$$$$
=\frac{1}{2 \pi \sigma_{x} \sigma_{y}} \exp \left(-\frac{(x-\bar{u} t)^{2}}{2 \sigma_{x}^{2}}-\frac{y^{2}}{2 \sigma_{y}^{2}}\right)
$$

$$
Q\left(z, t \mid H, t^{\prime}\right)
$$$$
=\frac{1}{(2 \pi)^{1 / 2} \sigma_{z}}\left[\exp \left(-\frac{(z-H)^{2}}{2 \sigma_{z}^{2}}\right)-\exp \left(-\frac{(z+H)^{2}}{2 \sigma_{z}^{2}}\right)\right]
$$

To evaluate the steady state concentration from a continuous point source, Eqs. (20) and (21) are substituted in Eq. (19) giving Eq. (22).

$$
\begin{aligned}
& C(x, y, z) \\
& =\int_{0}^{\infty} \frac{q\left(d e^{-\gamma t}+s e^{-(b+\gamma) t}\right)}{(2 \pi)^{3 / 2} \sigma_{x} \sigma_{y} \sigma_{z}} \exp \left(-\frac{(x-\bar{u} t)^{2}}{2 \sigma_{x}^{2}}\right)-\frac{y^{2}}{2 \sigma_{y}^{2}} \\
& \times\left[\exp \left(-\frac{(z-H)^{2}}{2 \sigma_{z}^{2}}\right)+\exp \left(-\frac{(z+H)^{2}}{2 \sigma_{z}^{2}}\right)\right] d t
\end{aligned}
$$

To evaluate the integration in Eq. (22), let

$$
C(x, y, z)=C_{1}(x, y, z)+C_{2}(x, y, z)+C_{3}(x, y, z)+C_{4}(x, y, z)
$$

where

$$
\begin{aligned}
& C_{1}(x, y, z) \\
& =\int_{0}^{\infty} \frac{q s e^{-(b+\gamma) t}}{(2 \pi)^{3 / 2} \sigma_{x} \sigma_{y} \sigma_{z}} \exp \left(-\frac{(x-\bar{u} t)^{2}}{2 \sigma_{x}^{2}}-\frac{y^{2}}{2 \sigma_{y}^{2}}-\frac{(z-H)^{2}}{2 \sigma_{z}^{2}}\right)
\end{aligned}
$$

$$
\begin{aligned}
& C_{2}(x, y, z) \\
& =\int_{0}^{\infty} \frac{q s e^{-(b+\gamma) t}}{(2 \pi)^{3 / 2} \sigma_{x} \sigma_{y} \sigma_{z}} \exp \left(-\frac{(x-\bar{u} t)^{2}}{2 \sigma_{x}^{2}}-\frac{y^{2}}{2 \sigma_{y}^{2}}-\frac{(z+H)^{2}}{2 \sigma_{z}^{2}}\right)
\end{aligned}
$$

$$
C_{3}(x, y, z)
$$$$
=\int_{0}^{\infty} \frac{q d e^{-(b+\gamma) t}}{(2 \pi)^{3 / 2} \sigma_{x} \sigma_{y} \sigma_{z}} \exp \left(-\frac{(x-\bar{u} t)^{2}}{2 \sigma_{x}^{2}}-\frac{y^{2}}{2 \sigma_{y}^{2}}-\frac{(z-H)^{2}}{2 \sigma_{z}^{2}}\right)
$$

and

$C_{4}(x, y, z)$

$=\int_{0}^{\infty} \frac{q d e^{-(b+\gamma) t}}{(2 \pi)^{3 / 2} \sigma_{x} \sigma_{y} \sigma_{z}} \exp \left(-\frac{(x-\bar{u} t)^{2}}{2 \sigma_{x}^{2}}-\frac{y^{2}}{2 \sigma_{y}^{2}}-\frac{(z+H)^{2}}{2 \sigma_{z}^{2}}\right)$

Each of the Eqs. (24)-(27) have been solved to get the full solution. Beginning with Eq. (23), the terms that represent the variances in the three dimensions depend on time. Therefore, the following assumptions were made: $a_{x}=2 K_{x x}$, $a_{y}=2 K_{y y}$, and $a_{z}=2 K_{z z}$. Then, Eq. (24) gives

$C_{1}(x, y, z)$

$$
\begin{aligned}
& =\frac{q s}{(2 \pi)^{3 / 2}\left(\sigma_{x} \sigma_{y} \sigma_{z}\right)^{1 / 2}} \int_{0}^{\infty}(t)^{-3 / 2} \exp \left(-\frac{(x-\bar{u} t)^{2}}{2 \sigma_{x} t}-\frac{y^{2}}{2 \sigma_{y} t}\right. \\
& \left.-\frac{(z-H)^{2}}{2 \sigma_{z} t}-(b+\gamma) t\right) d t
\end{aligned}
$$

Rearrangement of Eq. (28) yields

$$
\begin{aligned}
& C_{1}(x, y, z) \\
& =\frac{q s}{(2 \pi)^{3 / 2}\left(\sigma_{x} \sigma_{y} \sigma_{z}\right)^{1 / 2}} \\
& \int_{0}^{\infty}(t)^{-3 / 2} \exp \left[-\left(\frac{\left(x^{2}+\left(\frac{\sigma_{x}}{\sigma_{y}}\right) y^{2}+\left(\frac{\sigma_{x}}{\sigma_{z}}\right)(z-H)^{2}\right)}{2 \sigma_{x} t}\right.\right.
\end{aligned}
$$

$$
\left.\left.-\frac{2 \bar{u} x t}{2 \sigma_{x} t}+\frac{\bar{u}^{2} t^{2}}{2 \sigma_{x} t}+(b+\gamma) t\right)\right] d t
$$

Assuming $\beta^{2}=x^{2}+\left(a_{x} / a_{y}\right) y^{2}+\left(a_{x} / a_{z}\right)(z-H)^{2}$ and $\omega=(t)^{-1 / 2}$, Eq. (29) becomes

$$
\begin{aligned}
& C_{1}(x, y, z) \\
& =\frac{2 q s e^{\bar{u} x / a_{x}}}{(2 \pi)^{3 / 2}\left(\sigma_{x} \sigma_{y} \sigma_{z}\right)^{1 / 2}} \int_{0}^{\infty} \exp \left[-\left(\frac{\beta^{2} \omega^{2}}{2 a_{x}}+\frac{2 a_{x}(b+\gamma)+\bar{u}^{2}}{2 a_{x} \omega^{2}}\right)\right] d \omega
\end{aligned}
$$


This equation can be solved by using the following general form:

$\int_{0}^{\infty} \exp \left[-\left(a \omega^{2}+\frac{b}{\omega^{2}}\right)\right] d \omega=\frac{1}{2}\left(\frac{\pi}{a}\right)^{1 / 2} e^{-2(a b)^{1 / 2}}$

Substitution in Eq. (29) gives

$C_{1}(x, y, z)$

$=\frac{q s e^{\bar{u} x / a_{x}}}{2 \pi\left(a_{y} a_{z}\right)^{1 / 2} \beta} \exp \left[-\frac{1}{a_{x}}+\left(\beta^{2} \bar{u}^{2}+2 a_{x} \beta^{2}(b+\gamma)\right)^{1 / 2}\right]$

Using the approximation in Eq. (33) gives Eq. (34).

$$
(x+y)^{1 / 2} \cong x^{1 / 2}+\frac{1}{2} x^{-1 / 2} y
$$

$\left(\beta^{2} \bar{u}^{2}+2 a_{x} \beta^{2}(b+\gamma)\right)^{1 / 2}=\beta \bar{u}+\frac{a_{x} \beta(b+\gamma)}{\bar{u}}$

Eq. (34) is substituted in Eq. (32) giving the following formula:

$$
\begin{aligned}
& C_{1}(x, y, z)=\frac{q s}{2 \pi\left(a_{y} a_{z}\right)^{1 / 2} \beta} \\
& \exp \left[-\left(\frac{\bar{u}}{a_{x}}(\beta-x)\right)\right] \exp \left[-\left((b+\gamma) \frac{\beta}{\bar{u}}\right)\right]
\end{aligned}
$$

where

$\beta=x\left(1+\left(\left(a_{x} / a_{y}\right) y^{2}+\left(a_{x} / a_{z}\right)(z-H)^{2}\right) / x^{2}\right)^{1 / 2}=x+x\left(\left(a_{x} / a_{y}\right) y^{2}\right.$ $\left.+\left(a_{x} / a_{z}\right)(z-H)^{2}\right) /\left[2 x^{2}\right] \quad(36)$

Therefore,

$\beta-x=\frac{\left(\frac{a_{x}}{a_{y}}\right) y^{2}+\left(\frac{a_{x}}{a_{z}}\right)(z-H)^{2}}{2 x}$

Knowing that $\bar{u}=x / t$ and that the applied distance in the $x$ direction is much higher than that in the other two directions (i.e., $\left.x \gg\left(a_{x} / a_{y}\right) y^{2}+\left(a_{x} / a_{z}\right)(z-H)^{2}\right)$, it can be approximated that $\beta \cong x=u \bar{t}$. Substitution of Eq. (36) in Eq. (35) gives

$$
\begin{aligned}
& C_{1}(x, y, z)=\frac{q s}{2 \pi \bar{u}\left(a_{y} t\right)^{1 / 2}\left(a_{z} t\right)^{1 / 2}} \\
& \exp \left[-\left(\frac{y^{2}}{2 a_{y} t}+\frac{(z-H)^{2}}{2 a_{z} t}\right)\right] \exp \left[-\left((b+\gamma) \frac{x}{\bar{u}}\right)\right]
\end{aligned}
$$

Eqs. (25)-(27) can be solved using the same method. Substituting the values of $s, b$ and $d$ in Eq. (23) gives the full solution of the modified Gaussian plume equation as follows:

$$
\begin{gathered}
C(x, y, z)=\frac{q \lambda_{\gamma} e^{-\gamma \frac{x}{\bar{u}}}}{2 \pi \bar{u} \sigma_{y} \sigma_{z}} \exp \left(-\frac{y^{2}}{2 \sigma_{y}^{2}}\right) \\
{\left[\exp \left(-\frac{(z-H)^{2}}{2 \sigma_{z}^{2}}\right)+\exp \left(-\frac{(z+H)^{2}}{2 \sigma_{z}^{2}}\right)\right]}
\end{gathered}
$$

where $\lambda_{r}=\left[1+m \varphi_{s} \exp \left(-(x / \bar{u})\left(1+m \varphi_{s}\right) / \tau_{D}\right) /\left[1+m \varphi_{s}\right]\right.$. The correction factor $\lambda_{r}$ represents the fraction of the radionuclides that remains in the atmosphere at any distance downwind the smoke stack. It depends mainly on the volume fraction of the aerosols in the atmosphere $\varphi_{s}$, the dimensionless coefficient of adsorption $m$, the average wind speed $\bar{u}$, the distance downwind $x$, and the characteristic time of the mass transfer $\tau_{D}$. Consequently, the correction factor $\lambda_{r}$ at $x=0$ (and $t=0$ ) equals unity $\left(\lambda_{r o}=1\right)$, meaning that the radionuclide molecules have not yet transferred to the aerosol particles. For steady state conditions, the correction factor is given by $\lambda_{r, \infty}=1 /(1$ $+m \varphi_{s}$ ), which is independent of time, and only depends on the dimensionless coefficient of adsorption and the volume fraction of aerosols in the atmosphere. In addition, the correction factor $\left(1-\lambda_{r}\right)$ may be used to represent the fraction of radionuclides transferred to the aerosol particles.

\section{RESULTS AND DISCUSSION}

To represent the fraction of the transported radionuclides onto the atmospheric aerosols as a function of the distance downwind graphically using Eq. (38), iodine-131 was chosen as an example. Noguchi et al. (1990) studied the gaseous iodine adsorption by carbon-based ultrafine aerosols and estimated that the coefficient of diffusion $D_{G}$ and the linear adsorption coefficient $K^{\prime}$ of the iodine are equal to $0.08 \mathrm{~cm}^{2} \mathrm{~s}^{-1}$ and $10^{4} \mathrm{~m}$, respectively. Also, the specific surface area of the aerosol particles was assumed $100 \mathrm{~m}^{2} \mathrm{~cm}^{-3}$, and the density of the ultrafine aerosol particles $\rho_{s}$ was taken $1.2 \mathrm{~g} \mathrm{~cm}^{-3}$ according to Chen et al. (2010). Furthermore, the sticking probability $S_{p}$ was assumed unity and the average wind speed $5 \mathrm{~m} \mathrm{~s}^{-1}$.

The volume fraction of aerosol particles in the atmosphere $\varphi_{s}$ during dust events depends mainly on the concentration of the aerosols. However, nanoaerosols are characterized by their abundance and their low weight in the air; these two properties can lead to transport nanoaerosols for long distances from their main source. The number of aerosols in the atmosphere during a dust storm depends mainly on the vegetarian cover and the wind speed in the region of interest (Kurosaki and Mikami, 2003). The dust storm classification depends mainly on the dust concentration in the atmosphere within the dust storm period and can be governed by $\mathrm{PM}_{2.5}$, $\mathrm{PM}_{10}$ or TSP (total suspended particles). Table 1 shows the mean values and peak values of aerosol concentrations for $\mathrm{PM}_{2.5}, \mathrm{PM}_{10}$ and TSP for many dust storms around the world 
Table 1. Concentration of aerosols (TSP, $\mathrm{PM}_{2.5}$ and $\mathrm{PM}_{10}$ ) in the atmosphere during dust storms from several studies around the world.

\begin{tabular}{|c|c|c|c|}
\hline & $\begin{array}{l}\text { Concentration of Aerosol } \\
\left(\mu \mathrm{g} \mathrm{m}^{-3}\right)\end{array}$ & $\begin{array}{l}\text { Location and Date of } \\
\text { Occurrence }\end{array}$ & Reference \\
\hline \multirow{2}{*}{ Total Suspended Particles (TSP) } & 6000 (peak) & Northeast Asia (2000-2005) & Song et al. (2007) \\
\hline & 1021 (daily peak) & Palestine (1977) & Ganor et al. (1981) \\
\hline Particulate Matter less than & 9000 (peak) & Palestine (1998) & Alpert and Ganor (2001) \\
\hline \multirow[t]{8}{*}{$10 \mu \mathrm{m}\left(\mathrm{PM}_{10}\right)$} & 2568 (daily mean) & Palestine (2001-2012) & Krasnov et al. (2013) \\
\hline & 3986 (half hour peak) & Saudi Arabia (2012) & Alghamdi et al. (2015) \\
\hline & 1781 (peak) & Qatar (2015) & Saraga et al. (2017) \\
\hline & 1150 (daily mean) & $\operatorname{Iran}(2017)$ & Jaafari et al. (2017) \\
\hline & 5338 (peak) & Iran (2010) & Shahsavani et al. (2012) \\
\hline & 767 (daily peak) & China (2015) & Liu et al. (2014) \\
\hline & 5616 (peak) & Iran (2009) & Amanollahi et al. (2011) \\
\hline & 79600 (peak) & Cyprus (2015) & Mamouri et al. (2016) \\
\hline Particulate Matter less than & 700 (daily mean) & Palestine (2001-2012) & Krasnov et al. (2013) \\
\hline \multirow{4}{*}{$2.5 \mu \mathrm{m}\left(\mathrm{PM}_{2.5}\right)$} & 868 (half hour peak) & Saudi Arabia (2012) & Alghamdi et al. (2015) \\
\hline & 1569 (peak) & Qatar (2015) & Saraga et al. (2017) \\
\hline & 55.8 (daily mean) & Iran (2017) & Jaafari et al. (2017) \\
\hline & 910 (peak) & Iran (2010) & Shahsavani et al. (2012) \\
\hline
\end{tabular}

from several studies. Then by applying these assumptions in multiple dust storm events, the fraction of the adsorbed iodine into the atmospheric aerosols $\left(1-\lambda_{r}\right)$ as a function of the distance downwind the stack can be represented by Fig. 1. These results show that the fraction of the adsorbed iodine onto the atmospheric aerosols $\left(1-\lambda_{r}\right)$ is equal to zero at the origin of the smoke stack (at $x=0$ ) and increases within a few meters downwind to reach the steady state value (the maximum value). Also, the dust events of high aerosol densities reach the steady state value faster than the dust events of low densities. Jaafari et al. (2017) estimated that $\mathrm{PM}_{1} / \mathrm{PM}_{10}$ during dust events can reach 0.23 , meaning that 23 percent of $\mathrm{PM}_{10}$ has a size of particles less than $1 \mu \mathrm{m}$ and thus is constituted as nanoparticles. Thus, the dust storm that has a $\mathrm{PM}_{10}$ concentration of $4000 \mu \mathrm{g} \mathrm{m}^{-3}$ may have a $\mathrm{PM}_{1}$ concentration of $1000 \mu \mathrm{g} \mathrm{m}^{-3}$. Therefore, values of $\mathrm{PM}_{1}$ that were used to estimate the factor $\left(1-\lambda_{r}\right)$ in Fig. 1 ranged from 10 to $1000 \mu \mathrm{g} \mathrm{m}^{-3}$.

This study assumes that Knudsen number is constant and has a value of 1 for all dust storm densities. The fraction of the adsorbed iodine-131 onto atmospheric aerosols for dust events that have a density of $1000 \mu \mathrm{g} \mathrm{m}^{-3}$ increased rapidly from zero to reach the steady state value of 0.9 within the first 10 meters downwind. This means that the aerosols can adsorb 90 percent of the emitted iodine-131 from the smoke stack at this level aerosols' density. On the other hand, the dust events that have an aerosols' density of $10 \mu \mathrm{g} \mathrm{m}^{-3}$ will increase slowly from zero to reach the maximum value of 0.07 at $x=50 \mathrm{~m}$, meaning that it takes more time to reach the steady state and the adsorbed amount of iodine-131 on the atmospheric aerosols that is much lower than that for the denser dust events. Fig. 2 shows the relationship between the rate of adsorption of the radioactive gas into the atmospheric aerosols as a function of time for several values of sticking probability $S_{p}$ at a specific value of aerosols' density $\rho_{s}$ that equals $1000 \mu \mathrm{g} \mathrm{m}^{-3}$. These results show that as the sticking probability decreases, the time required to reach the steady state value of $\left(1-\lambda_{r}\right)$ also decreases. This is due to the fact that as the sticking probability value decreases, the number of effective collisions between the radioactive gas and the aerosol particles decreases, which leads to decreasing the time required to reach the steady state value. The theoretical results of this study make an agreement with the experimental results of Noguchi et al. (1988) and Noguchi et al. (1990). Their studies estimated the rate of adsorption of gaseous radioactive iodine-131 on atmospheric aerosol particles.

\section{CONCLUSION}

The Gaussian plume equations were modified in this study to include the potential impact of the atmospheric aerosols on the transported gaseous radionuclides from the nuclear power plant based on the flux-matching theory approaches by assuming that the adsorption coefficient of the gaseous radionuclides on the atmospheric nanoaerosols in the reaction term of the general diffusion-dispersion equation is time-dependent, and the size of the aerosol particles has the same order of magnitude of the mean free path of air molecules (transition regime; $K n \cong 1$ ).

Several dust storms including the Khamaseen cyclones were characterized in this study from the literature; this characterization included the particle size distribution of several dust storms (TSP, $\mathrm{PM}_{2.5}$ and $\mathrm{PM}_{10}$ ) as shown in Table 1 that which shows that the density of $\mathrm{PM}_{10}$ in the atmosphere during dust events in Palestine (Khamaseen cyclones) had reached a peak and daily mean values of $9000 \mu \mathrm{g} \mathrm{m}^{-3}$ (Alper and Ganor, 2001) and $2568 \mu \mathrm{g} \mathrm{m}^{-3}$ (Krasnov et al., 2013), respectively. Also, Saraga et al. (2017) estimated that the peak value of concentration of $\mathrm{PM}_{2.5}$ in the atmosphere during a dust event in Qatar in 2015 had reached $1569 \mu \mathrm{g} \mathrm{m}^{-3}$. Krasnov et al. (2013) estimated that the daily mean value of 


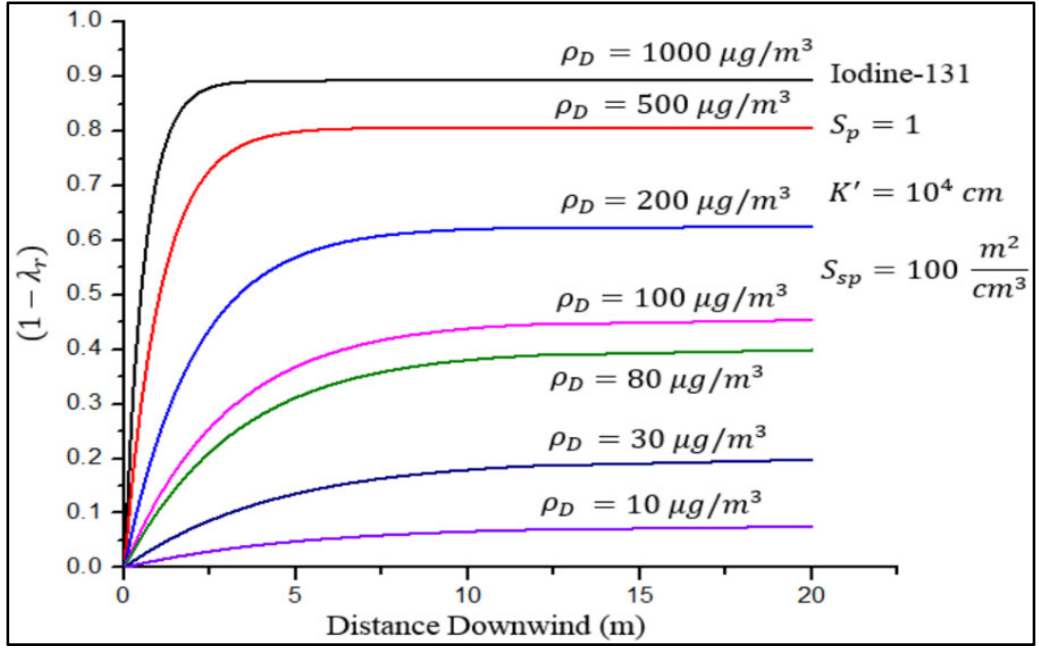

Fig. 1. Fraction of the adsorbed iodine-131 into the atmospheric aerosols $\left(1-\lambda_{r}\right)$ as a function with the distance downwind of the stack for different values of mass concentrations of aerosols $\left(\rho_{D}\right)$.

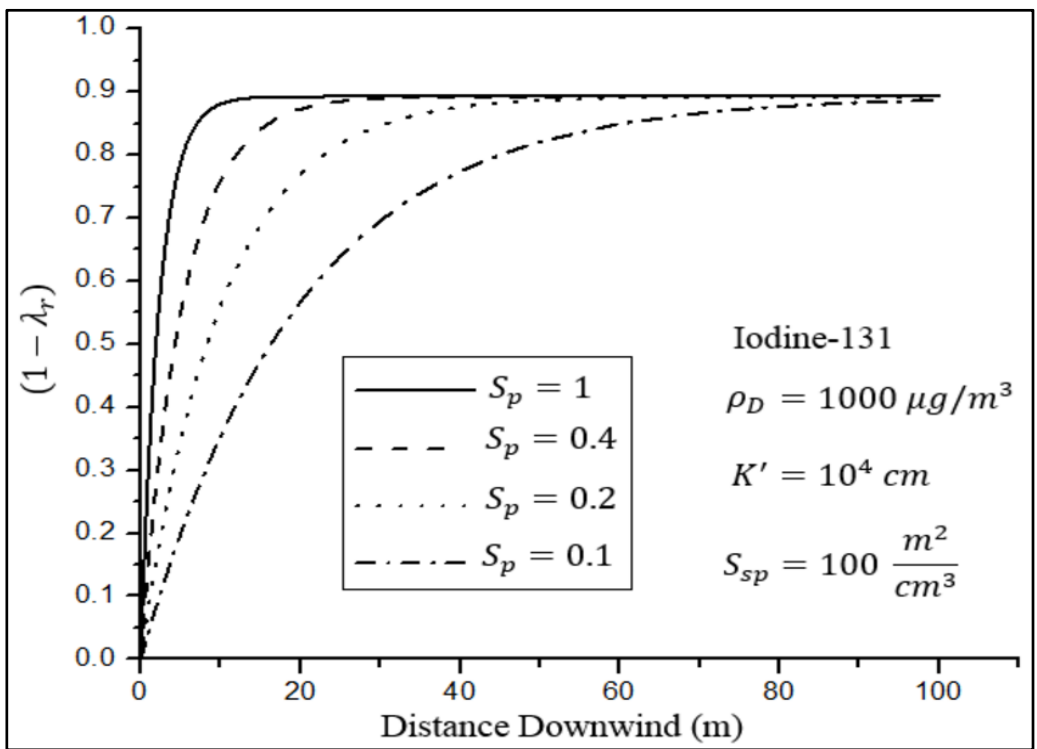

Fig. 2. Fraction of the radioactive iodine-131 into the atmospheric aerosols as a function with time for several values of sticking probability $S_{p}$ at the aerosols' density of $1000 \mu \mathrm{g} \mathrm{m}^{-3}$.

concentration of $\mathrm{PM}_{2.5}$ in the atmosphere during dust events in Palestine from 2011 to 2012 had reached $700 \mu \mathrm{g} \mathrm{m}^{-3}$. Dust storms' concentrations used in the results of this study were taken to satisfy the limitation of $K n \cong 1$.

This modification introduced the correction factor $\left(\lambda_{r}\right)$ into the Gaussian plume equation which was applied to the fraction of the remaining gaseous radionuclides in the atmosphere at any point downwind as shown in Eq. (38). Also, this study indicates that the $\left(1-\lambda_{r}\right)$ values range from less than 0.1 for dust events with small concentrations of nanoaerosols $\left(\mathrm{PM}_{1}=10 \mu \mathrm{g} \mathrm{m}^{-3}\right)$ to more than 0.9 for the heavy dust storms $\left(\mathrm{PM}_{1}=1000 \mu \mathrm{g} \mathrm{m}^{-3}\right)$ as shown in Fig. 1 .

\section{REFERENCES}

Abdulkader, M.A., Mustafa, A.K. and Hani, A.K. (2009).
Characterization of the Khamaseen (spring) dust in Jordan. Atmos. Environ. 43: 2868-2876.

Alghamdi, M.A., Mansour, A., Magdy, S., Maria, A.R., Abdulrahman, K.A., Mahmoud, A.H. and Mamdouh, I.K. (2015). Characterization and elemental composition of atmospheric aerosol loads during springtime dust storm in western Saudi Arabia. Aerosol Air Qual. Res. 15: 440453.

Alpert, P. and Ganor, E. (2001). Sahara mineral dust measurements from TOMS: Comparison to surface observations over the Middle East for the extreme dust storm. J. Geophys. Res. 106: 18275-18286.

Amanollahi, J., Kaboodvandpour, S., Abdullah, A.M. and Ramli, M.F. (2011). Accuracy assessment of moderate resolution image spectroradiometer products for dust storms in semiarid environment. Int. J. Environ. Sci. 
Technol. 8: 373-380.

Athanasopoulou, E., Protonotariou, A., Papangelis, G., Tombrou, M., Mihalopoulos, N. and Gerasopoulos, E. (2016). Long-range transport of Saharan dust and chemical transformations over the eastern Mediterranean. Atmos. Environ. 6: 1-36.

Chen, S.C., Tsai, C.J., Chou, C.C.K., Roam, G.D., Cheng, S.S. and Wang, Y.N. (2010). Ultrafine particles at three different sampling locations in Taiwan. Atmos. Environ. 44: 533-540.

Doronzo, D.M. Khalaf, E.A., Dellino, P., de Tullio, M.D., Dioguardi, F., Gurioli, L., Mele, D., Pascazio, G. and Sulpizio, R. (2014). Local impact of dust storms around a suburban building in arid and semi-arid regions: Numerical simulation examples from Dubai and Riyadh, Arabian Peninsula. Arabian J. Geosci. 8: 7359-7369.

Doronzo, D.M. de Tullio, M.D., Pascazio, G., Dellino, P. and Liu, G. (2015). On the interaction between shear dusty currents and buildings in vertical collapse: Theoretical aspects, experimental observations, and 3D numerical simulation. J. Volcanol. Geotherm. Res. 302: 190-198.

Elperin, T., Fominykh, A. and Krasovitov, B. (2013). Isothermal absorption of soluble gases by atmospheric nanoaerosols. Phys. Rev. E 87: 012807.

Elperin, T., Fominykh, A., Katra, I. and Krasovitov, B. (2017). Modeling of gas adsorption by aerosol plumes emitted from industrial sources. Process Saf. Environ. Prot. 111: 375-387.

Elperin, T., Fominykh, A., Katra, I. and Krasovitov, B. (2018). Scavenging of radioactive gases due to adsorption by atmospheric nanoaerosols. Meteorol. Atmos. Phys. 131: 1225-1233.

Engelstaedter, S., Tegen, I. and Richard, W. (2006). North African dust emissions and transport. Earth Sci. Rev. 79: 73-100

Environmental Protection Agency (EPA) (2000). Radiation protection at EPA. Office of Radiation and Indoor Air. EPA, USA.

Fuchs, N.A. (1964). The mechanics of aerosols. Pergamon Press, Oxford.

Ganor, E. and Mamane, Y. (1981). Transport of Saharan dust across the eastern Mediterranean. Atmos. Environ. 16: 581-587.

Hales, J.M. (2002). Wet removal of pollutants from Gaussian plumes: Basic linear equations and computational approaches. J. Appl. Meteorol. 41: 905-918.

Jaafari, J., Naddafi, K., Yunesian, M., Nabizadeh, R., Hassanvand, M.S., Ghozikali, M.G., Nazmara, S., Shamsollahi, H.R. and Yaghmaeian, K. (2018). Study of $\mathrm{PM}_{10}, \mathrm{PM}_{2.5}$ and $\mathrm{PM}_{1}$ levels in during dust storms and local air pollution events in urban and rural sites in Tehran. Hum. Ecol. Risk Assess. 42: 482-493.

Krasnov, H., Itzhak, K., Petros, K. and Michael, D.F. (2013). Contribution of dust storms to $\mathrm{PM}_{10}$ levels in an urban arid environment. J. Air Waste Manage. Assoc. 64: 8994.

Kurosaki, Y. and Mikami, M. (2003). Recent frequent dust events and their relation to surface wind in East Asia.
Geophys. Res. Lett. 30: 1-4.

Liu, Q., Yanju, L., Jianxin, Y., Meigen, Z. and Tingting, Z. (2014). Chemical characteristics and source apportionment of $\mathrm{PM}_{10}$ during Asian dust storm and non-dust storm days in Beijing. Atmos. Environ. 91: 85-94.

Loyalka, S.K. (1983). Mechanics of aerosols in nuclear reactor safety: A review. 12: 1-56.

Lushnikov, A.A. and Kulmalan M. (2004). Flux-matching theory of particle charging. Phys. Rev. E 70: 046413.

Mamouri, R.E., Nisantzi, A., Ansmann, A. and Hadjimitsis D.G. (2016). Extreme dust storm over the eastern Mediterranean in September 2015: Lidar vertical profiling of desert dust at Limassol. Atmos. Chem. Phys. 16: $13711-13724$

Martin, D.O. (1976). The change of concentration standard deviation with distance. J. Air Pollut. Control. Assoc. 26: $1-4$.

Masters, G.M. and Ela, W.P. (2007). Introduction to environmental engineering and science, 3rd edn. PearsonPrentice Hall, Upper Saddle River, NJ.

Noguchi, H. Murata, M. and Suzuki, K. (1988). Adsorption of radioactive $I_{2}$ gas onto Fly-ash aerosol. Jpn. J. Health Phys. 23: 19-26.

Noguchi, H., Murata, M. and Suzuki, K. (1990). Adsorption of radioactive iodine gas onto atmospheric aerosol. Jpn. J. Health Phys. 25: 209-219.

Pasquill, F. (1961). The estimation of the dispersion of windborne material. Meteorol. Mag. 90: 33-62.

Saraga, D., Maggos, T., Sadoun, E., Fthenou, E., Hassan, H., Tsiouri, V., Karavoltsos, S., Sakellari, A., Vasilakos, C. and Kakosimos, K. (2017). Chemical characterization of indoor and outdoor particulate matter $\left(\mathrm{PM}_{2.5}, \mathrm{PM}_{10}\right)$ in Doha, Qatar. Aerosol Air Qual. Res. 17: 1156-1168.

Seinfeld, J.H. and Pandis, S.N. (1998). Atmospheric chemistry and physics: From air pollution to climate change, 1st edn, John Wiley \& Sons, Inc., New Jersey.

Seinfeld, J.H. and Pandis, S.N. (2006). Atmospheric chemistry and physics: From Air Pollution to Climate Change, 2nd edn., Wiley, New York.

Shahsavani, A., Naddafi, K., Jafarzade Haghighifard, N., Mesdaghinia, A., Yunesian, M., Nabizadeh, R., Arahami, M., Sowlat, M.H., Yarahmadi, M., Saki, H., Alimohamadi, M., Nazmara, S., Motevalian, S.A. and Goudarzi, G. (2012). The evaluation of $\mathrm{PM}_{10}, \mathrm{PM}_{2.5}$, and $\mathrm{PM}_{1}$ concentrations during the Middle Eastern Dust (MED) events in Ahvaz, Iran, from April through September 2010. J. Arid. Environ. 77: 72-83.

Song, Z., Wang, J. and Wang, S. (2007). Quantitative classification of northeast Asian dust events. J. Geophys. Res. 112: 1-8.

Tindall, J.A., Kunkel, J.R. and Anderson, D.E. (1999). Unsaturated zone hydrology for scientists and engineers. Upper Saddle River, New Jersey.

Turner, D.B. (1970). Workbook of atmospheric dispersion estimates. U.S. Environmental Protection Agency Report AP-42, U.S. Government Printing Office, Washington, D.C.

U.S. Nuclear Regulatory Commission (NRC) (1977). Regulatory Guide 1.111, Methods for estimation 
atmospheric transport and dispersion of gaseous effluents in routine releases from light-water-cooled reactors. USNRC Office of Standards Development, Washington, D.C.
Received for review, September 4, 2019

Revised, December 9, 2019 Accepted, December 10, 2019 